\title{
Flaubert y la ilusión del Realismo
}

\author{
POR ÂNDRÉ COYNÉ
}

Más que una conferencia sobre Flaubert he aceplado presentaros algunas reflexiones en torno a la palabra "Realismo", indistintamente aplicada al arte del novelista por los críticos profesionales, se diría que con el fin único de catalogar a un creador, es decir limitarlo, rebajarlo, negando to que le diferencia $y$, en buena cuenta, lo constituye. Como las otras palabras "passe-partout" del vocabulario crítico, la palabra "realismo" en su acepción estricta nada significa o la aplicaremos solamente a aquellos escritores de segundo o tercer orden que escriben movidos por teo. rías o por cálculos, y no por la necesidad arrolladora, si bien muchas veces aterradora deda auténticacatección.

A pesar de que es Lg Educación Sentimental la obra máxima de Flaubert (Y lal vez la novela cumbre de nuestro siglo XIX), lomaré mis ejemplos de Madame Bovary ya que celebramos su centenario y por tratarse de una obra más conocida, familiar a todos los públicos, amén de ser la que reveló a su autor, de la noche a la mañana lo impuso a la atención general, hasta de la Justicia del Substitulo Pinard.

No por mera casualidad hemos celebrado este año, al mismo tiempo que de dos libros excelsos, el centenario de las "causas" abiertas en contra de ellas. Que el Fiscal que alegó contra Madame Bovary y contra Las Flores del Mal haya sido el mismo, cuyo nombre acabo de recordar, no deja de ser significativo, y que el tribunal condenara a Baudelaire cuando meses atrás se había absuelto a Flaubert, puede indicar el "endurecimiento", o la inconsecuencia de la justicia, o simplemente que un poeta más absoluto resulta también más escandaloso que cualquier otro escritor. De todos modos, la comparación se impone, y nadie se extraña- 
rá de que el mejor artículo escrito en 1857 sobre la novela de Flaubert, "lleva la firma de Baudelaire -artículo de singular penetración, y al cual hoy todavia muy poco tendríamos que agregar.

En ambos procesos y en la requísitorias de Pinard, lo incriminado eran ciertas pinturas tachadas precisamente de "realistas", sin que entrara en tela de juicio su categoría "artística", sino las consecuencias "morales". Para los acusadores y los jueces el realismo está, pues, en, los hechos o mejor dicho en la pintura de cierta categoría de hechos, cuya existencia no piensa en negar, pero antes los cuales prefieren correr una cortina de silencio o de tinieblas. Sin embargo los acusados son los dos máximos escritores contemporáneos, exclusivamente preocupados, como nadie en su tiempo, por la Hermosura y por el Arte. Podríaos advert tir cómo, hábilmente, en un párrafo de su artículo sobre Flaubert no desprovistos de amarga ironía, Baudelaire se felicita de la imparcialidad de los magistrados que han "indultado" a Madame Bovary, ya que aun si hubiesen descubierto en el libro "algo verdaderamente reprobable", es de creer que lo "amnistiaran" de todas maneras "en favor y agradecimiento de la BELLEZA que lo viste. Extraña contianza, dirían algunos, en el buen gusto de la magistratura, cuando la "belleza" de las Flores del Mal no lograba impedir por su parte una sentencia condenatoria. En realidad, Boudelaire aprovécha el elogio de lós jueces para mejor exaltar lo que únicamente le importa, la "alia tendencia poética", "notable preocupación por la Belleza:, que al lopone una vez más a la vehemente codicia de "una sociedad que definitivamente ha abjurado de todo amor espiritual y que a nada se interesa fuera de sus vísceras" - "una sociedad absolutamente gastada- peor que gastada- embrutecida y ávida, que tiene horror a la ficción y sólo persigue la posesión". El acusado se ha trocado en acusador y celebra la benevolencia de los magistrados sólo para poder proclamar el culto de lo Bello y, cuando lodos hablan de Moral al enjuiciar una obra de arte, para protestar contra la "eterna $\theta$ incorregible confusión de las funciones y los géneros": "La lógica de la obra cubre todas las postulaciones de la moral, y es el lector el que ha de sacar las conclusiones de la conclusión".

Ningún tema, desde luego, más trillado que el de Madame Bovary. Pensemos en la importancia del adulterio en las obras "delicadas" y "esmeradas" de los novelistas de moda como Jules Sandeau u Octave Feuillet - pero cuyo esmero y delicadeza 
consistía en disimular ciertas cosas demasiado concretas, o anegarlas en chorros de sutilezas morales y sentimentales. Lo reprensible en la obra de Flaubert no era, pues, una "situación" escandalosa, sino la manera de considerar y de "tratar" esa situación. Acudiremos otra vez a Baudelaire que, con su lucidez acostumbrada, nos proporciona además un punto de vista contemporáneo, de importancia, sobre todo. cuando, después de un siglo de literatura novelesca, los "audacias" de Madame Bovary (co. mo la famosa escena del corsé, incriminada por Pinard) podrían parecernos hoy día inofensivas, hasta jexcesivamente discretas. Sin embargo varios críticos de 1857, entre los sensibles a la belleza de la novela censuraban como el mayor defecto la ausencia de todo personaje "que represente la moral, que exprese la conciencia del autor". "¿Dónde está, preguntaban, el personaje proverbial y legendario, encargado de explicar la fábula y de dirigir la inteligencia del leclor? En otros términos ¿dónde está el requisitorio? Quienes no se asusiaban de la "crudeza" (poniendo crudeza entre comillas) de algunos párrafos, hubiesen deseado de todos modos que el autor interviniera. para de-solidarizarse de los hechos o sacar en claro la moraleja.

Reprobable entonces, la actitud del escritor impasible ante su obra, impasibilidad que revela un espíritu denigrador "para el cual no exisle nada sagrado" y que ninguna violación de las leyes humanas o divinas logra conmover o indignar. (Lo único que lo indignaria, sería más biencló estulticia v de scualquier origen). Mucho se ha hablado de la creación "impersonal" de Flaubert. Nosotros preferiríamos insistir sobre la extraordinaria personalidad oculta tras la aparente impersonalidad y generadora de un estilo que nadie ha podido superar, ni igualar, como sucede con todos los estilos auténticos para siempre a cublerto de la imitación - de la vejez. Volveré sobre la cuestión del estilo que, es en buena cuenta, la esencial. Por ahora bástenos advertir que en un principio, y para mentes poco preparadas a juzgar de la calidad artística de las obras, hay confusión entre el vocablo "realismo" y la pintura de la más baja realidad, o la más inmoral, con evidente complacencia en las taras y los vicios, al menos en el aspecto trivial, cuotidiano hasta la vulgaridad, de las aventuras humanas. Es cierto que, a partir digamos de 1845 , en reacción contra los grandes sentimientos románticos y toda clase de idealización estética, algunos escritores y artistas, entre ellos Murger, 
Champfleury, el poeta del trabajo Pierre Dupont, el pintor Courbet, reunidos en torno al periódico Le Corsaire-Santa, habían reivindicado el derecho de transcribir la vida tal cual, sin distinguir entre los hechos, reproduciéndola fría e integralmente; y como cada cual no reproduce bien sino lo que mejor conoce, ellos que salían de la pequeña burguesía o del pueblo, para concluir en la bohemia parisina, se complacían en estos ambientes hasta la fecha poco literarios. No menos cierta es la colaboración de Baudelaire en el Corsaire-Santa y su amistad por Champfleury y sobre todo Dupont. Pero lo único que, en el fondo, Baudelaire había tenido en común con sus compañeros del Corsaire, era la afición por la "vida moderna" -un sentido, en él más agudo, ya que exencialmente poético, de la "modernidad". En cuanto a la batalla consiguiente del "realismo", Baudelaire nunca la tomó en serio- convencido de que Champfleury inventara la palabra en son de broma, aprovechando la incoherencia general, y como una contraseña mágica, sin sentido determinado; "lanzada la bola, fué preciso creer en ella". En el artículo sobre Madame Bovary, el poeta se queja de que "ulltimamente nuestros oídos han s1do abrumados por unas chacharas de escuela del todo pueriles" sobre "cierto procedimiento literario llamado realismo": el creador original no necesita de nuevos "poncifs" para desterrar los antiguos. Y en un proyecto para un artículo, que nunca llegó a terminar, pero que evidencia su cansancio y su absoluto desprecio por las discusiones sobre escuelds (literariass ( mo tiempo que la altura de sus propias "convicciones", en un proyecto de artículo, probablemente de 1855, titulado $Y a$ que de realismo se trata, Baudelaire, despiés de señalar los orígenes del vocablo y de lamentar la absurda resonancia alcanzada, rechaza desdeñosamente el epíteto de "realista" que también $a$ él le lanzaran, por más que se haya aplicado a desmerecerlo, hasta que visiblemente fastidiado, cambia de pronto el sentido de la palabra Y proclama: "Todo buen poeta siempre fué realista", agregando su famosa fórmula definitoria de la poesía: "La Poesía es lo más real que existe, totalmente verdadero, sólo en otro mundo. Realismo poético incomparable, no necesito advertirlo, con él de Champfleury y de su escuela.

No olvido que estoy hablando de Madame Bovary. Champłleury era un hombre hábil, persuasivo, pero un mediocre escritor, al menos un escritor carente de imaginación ( $y$ \& Flaubert le sobra imaginación). El realismo documental que preconizaba, 
"escuela del daguerrotipo" acumulando detalles verdaderos, sin seleccionar ni prolongarlos, implicaba asimismo la negación de todo estilo, la despreocupación más absoluta por la forma. Flaubert, al contrario, ¿quién lo ignora? fué un maniático de la forma hasta desesperarse por haber tenido que dejar dos genitivos en una misma frase. No vamos a exigir de todo escritor que amolde su estilo al de Flaubert. No hay uno, sino muchos estilos; y a cada escritor original le corresponde encontrar el suyo propio, es decir la manera de expresar con máximo resultado la experiencia, la visión del mundo o del hombre que va a proponemos. No podríamos definir exactamente lo que es el estilo, pero sí sabemos cuando existe y cuando no - después de todo, algo común tienen los estilos más diversos, hasta opuestos: se imponen a nosotros, llevan el sello de lo auténtico, nos dan la sensación de una plenitud, la sensación de que lo dicho no podía ser dicho de otra forma sin perder su efecto, luego su verdad. Desdo el estilo fuerte, barroco de Flaubert, hasta el estilo suntuoso o inesperado de algunos textos surrealisias, por más que sorprenda el acercamiento.

No bastan las buenas intenciones, ni una sinceridad inmediata para que nos convenza una página escrita. La sinceridad consciente no se confunde forzosamente con la autenticidad, y hay que luchar mucho, a veces, para alcanzar la segunda. Nos cuentan con que el infierno está empedrado de buenas intenciones; lo mismo pasa con lg historia de la literatura. Advertencia que no deberían olvidar tantos escritores noveles, cuyo cariño por las cosas que los rodean, ciega muchas veces sobre las peculiares condiciones de la escritura. Contra los volatineros que consideran a la literatura como un oficio cualquiera y se embriagan de pala. bras huecas o altisonantes, es necesario afirmar la primacía de la experiencia, pero cada forma de la actividad humana tiene sus leyes de acuerdo con el objeto perseguido y para quien escribe es la mayor o menor autenticidad función de la expresión - no toda experiencia logra trascender los umbrales de alma individual; requiere para ello una expresión adecuada: la credibilidad y el contagio. Contagio que sólo se realiza mediante el estilo.

Al hablar de Flaubert, Baudelaire lo califica de poeta. El estilo hace de todo escritor un poeta. Se presentan casos límites, donde la verdad poética surge de las cosas mismas, de clerto aspesto de las cosas y ocurre a veces que el escritor más despreocupado se lleva nuestra convicción sólo por haber dirigido su mirada, 
con la debida curiosidad hacia algunas "rarezas" o excentricidades directamente ofrecidas por la vida. No hace mucho que la revista Bizarre, dedicada a reunir cuentos tantásticos y documentos insólitos, reproducía unas sugestivas páginas parisinas de Champlleury $y$, al enjuiciarlo en 1857. Baudelaire reconocía que éste ocasionalmente había dirigido "un binóculo poético" sobre los sucesos, los azares burlescos o patéticos de la existencia, pero agregaba que, casi a pesar suyo, en contradicción con sus teorías: "un binóculo poético -más poético de lo que él mismo cree". En realidad los aciertos ocasionales son muy pocos y el estilo, raras veces lo confiere la vida bruta; sino que lo debemos a la selección y a la práctica; el "binóculo" de Champfleury podía resultar poético porque se dejaba sorprender por lo desconcertante del espectáculo callejero; la literatura, por lo general, tiene otras exigencias.

¿Cómo no observar entonces que el realismo de 1850, al igual que el neo-realismo de nuestrós días, con el pretexto de la fotogratía, se olvida de los fines propios de la creación literaria y se aviene a consideraciones ajenas, las más bellas de orden práctico. Era el doctrinario de la escuela, Duranty, fundador de una revista polémica del mismo nombre: Realismo quien proclamaba: "El artista persigue una meta filosófica práctica... En lo verdadero se le ocurrió que había que prohibir la poesía, y el blanco principal de sus ataques en la aludida revista fué precisamente Flaubert; el libro más a menado denuncidd6: Marade Bovary. Las razones son interesantes: lo que Duranty reprobaba, era el sistema de descripción obstinada" - la obstinación y la ausencia de toda emoción o sentimiento. $Y$ ya vemos si persistimos en hablar del realimos de Flaubert, se trata de un realismo muy particular, que los realistas ortodoxos no admiten, un realismo de artista o de poeta, extremo opuesto de lo que designa ordinariamente la palabra. La "descripción obstinada" no tiene por objeto calcar, reproducir una realidad, que no existe sino reflejada por un ojo humano ( $y$ cuanto más exigenter el ojo, tanto más convincente la realidad). La "manía" descriptiva del novelista y la implacable "objetividad" son la primera consecuencia de una elección, el primer resultado de un "éclairage" -de una tluminación particular.

Flaubert solía citar una frase del naturalista Buffon: "La manera como se enuncia una verdad, es más útil a la humanidad que la misma verdad". Y ante el éxito de Madame Bovary, un tan. to escandaloso, él se quejaba de un equívoco: como los magistra- 
dos que lo enjuiciaron, los lectores o las lectoras que lo celebraban, daban mayor importancia a la historia de Roma, al "vaudeville", que a la manera de escribir. Después de luchar por espacio de siete años con la materia rebelde del lenguaje, el escritor se sentía defraudado más aún que por sus acusadores por los mediocres admiradores, que parecían dar razón a los primeros, gustando solamente de una anécdota sentimental que él ni siquiera inventara.

Doble equívoco, ya que a otra categoría de lectores hasta la anécdota no les llegaba a interesar, porque tras la riqueza indiferente de la forma no acertaban a descubrir las intenciones del autor. Algunos críticos de la época nos ofrecen el testimonio de su desconcierto ante un libro inútil, gratuito y exageradamente recargado, voluntariamente monótono, a pesar o a causa de la ostentación de la escritura, para narrar un episodio de vida burguesa, de una evidente trivialidad.

De todos modos el tema de la novela retenía la atención, y nadie oía la protesta del escritor que refieren en su Diario los hermanos Goncourt: "La historia, la aventura no me importa. Cuando escribo una novela, quiero solamente expresar un colorido, un matiz determinado... En Madame Bovary mi único propósito fué traducir el color enmohecido de la existencia de las cucarachas"; "la' fábula tan poco me importaba que primero pensé en otra, de mismo tono y ambiente: la historia de une solterona casta y cucufata: Luego comprendi que ésta seríc un personaje imposible..." -frase la última que introduce una salvedad, y nos indica que la anécdota de la novela no es completamente indiferente, pero lo esencial sigue siendo la primera parte de la declaración, la cual resulta para nosotros de una singular actualidad.

Con motivo del centenario, hemos leído más de un artículo reticente en cuanto al interés duradero de Madame Bovary: el libro habría envejecido. Una nueva lectura me ha convencido personalmente de lo contrario, y por lo tanto, de la exactilud de las observaciones de Flaubert. Ha muerto hace tiempo el escándalo que el libro provocara y puede ser que la "situación" de Madame Bovary se haya vuelto algo anacrónica -aunque tampoco de eso estoy seguro; pero, si bien estamos acostumbrados a temas de mayor "crudeza", el "atrevimiento" de Flaubert, han dejado de impresionarnos, nos encontramos en mejores condiciones para apreciar debidamente la transfiguración estética, sentir la Belleza de las líneas y de las tiguras, el Misterio de los colores al mismo tiem- 
po de la Ratio última de la obra, inadvertido de la crítica apresurada. Contra lo que muchos podrán creer, la lectura de Madame Bovary, si nos desprendemos de cierta materialidad, no es lectura fácil para adolescentes o solteronas románticas -requiere no digamos cultura, sensibilidad a los valores propios del Arte y aceptación de su autonomía.

No es un escritor realista sino un poeta, el que se manifiesta a lo largo de las páginas por la exuberancia de las imágenes, todas nuevas y de una variedad ilimitada, -desde la primera, acerca de la gorra de Charles Bovary, pobre cosa indescriptible y cuya "muda fealdad" tenía "honduras de expresión" tales como las hay en "el rostro de un imbécil". Cuando no son las cosas las que revelan angustias y tormentos humanos, son nuestros sentimientos, nuestras ideas, nuestras facultades las que adquieren las indiferencia o la vana agitación de las cosas: "La conversación de Carlos era lisa como la acera de la calle... - La vida (de Emma)... fría como un desván cuyo ojo de buey mira hacia el norte, y el tedio, araña silenciosa, hilaba su tela en la sombra por todas las esquinas de su corazón... - Su voluntad, como el velo de su sombrero que sujeta un cintillo, palpitaba a todos los vientos"... etc.

De vez en cuando metáloras más.largas se prolongan y desarrollan con una extraordinaria precisión que no excluye, sino al contrario, favorece la "divagación" y el ensueño. Quiero citar una completa -en el capítulo 7 de la segunda parte, después de la primera separacjón de Emmai y de León quesva a terminar sus estudios a París: "Desde entonces el recuerdo de León fué (para Emma) como el centro de su hastío; donde chisporroteaba con más vigor que una estepa de Rusia el fuego prendido por viajeros y abandonado en la nieve. Ella se precipitaba en su dirección, se acurrucaba, y removía delicadamente las ascuas a punto de apagarse; iba buscando alrededor cuanto podía avivarlas; y todo lo recogía- las reminiscencias más lejanas como las inmedialas ocasiones, lo que experimentaba y lo que imaginaba, sus ansias de goce que se dispersaban, sus proyectos de felicidad que crujían en el viento como enramada seca, su virtud estéril, sus esperanzas caídas, el jergón doméstico - todo lo reunía y lo utilizaba para calentar su tristeza. No obstante las llamas se fueron sosegando, sea que agotasen la provisión o que el amontonamiento se volviese demasiado considerable. Poco a poco el amor se apagó con la ausencia, el pesar fué sofocado por la costumbre; y el fulgor de incendio que vestía de púrpura su cielo pálido, empezó a cu- 
brirse de sombra hasta borrarse gradualmente. Luego su concien. cia adormecida le hizo confundir la repugnancia hacia el marido con la aspiración por el amante, los ardores del odio con el recaJentar de la ternura; pero, como el huracán seguía soplando y la pasión se consumió hasta la ceniza, y ningún socorro se presentó ni asomó el sol, de todos lados la noche se hizo absoluta, y Emma quedó perdida en un frío horrible que la atravesaba". Una imagen tan trillada como la del "fuego del amor". Flaubert parece descubrirla por primera vez y no la suelta sino después de agotarla, totalmente renovada según la tonalidad especial de la novela; en un amblente de fracaso inevitable y la universal caducldad.

La novela no reproduce una supuesta realidad sino que el autor proyecta sobre los seres y las cosas una luz especial que marca las sombras y destaca arbitrariamente ciertas formas -arbitrarlamente, es decir artísticamente, de acuerdo con un proyecto fundamental, $y$ una intuición primitlva. Entonces la vista -la simple vista utilitaria se rinde a la visión - poco falta para que digamos a la videncia. La descripción minuclosa de los objetos como de los personajes, muy lejos de todo propósito realista, se inspira en la atmósfera general de la obra, con largas y profundas resonancias, que no están ni en los unos nl en los otros, aunque de ellos surgen y $\mathrm{g}$ ellos parecen pegarse.

Tomaré un solo ejemplo: la descripción de la "piéce-montée" -la torta de boda-lo más relevado de-Fa comida de matrimonio de Emma y Charles. Bovary: Flaubert no nos perdona ningún detalle, desde el templo con pórticos de la base hasta los dos amores mecidos en un columpio que rematan la obra -descripción fría, objetiva (¿cómo no usar la palabra una vez más?)uno creería que el escritor desaparece detrás del objeto y se limita a copiarlo con la más severa precistón. La descripción acom. paña una frase también a primera vista inocente y objetiva: "a la hora del postre trajeron una torta que fué saluda con gritos" -se trata, desde luego, de gritos de admiración de los comensales: y diríamos, pues, que para mejor representar esa admiración, Flaubert, simple testigo, emprende la descripción de aquello que la provoca.

Pero no: hay más bjen un violento contraste entre lo que podemos imaginar de la admiración bulliciosa de campesinos ya pasablemente achispados por los vinos $y$ los humos de la comida y 
la aplicación del escritor en apuntar como para un inventario notarial los detalles exactos del pastel; si tal o cual de los en la boda presentes intentara traducir con palabras lo que todos experimentan, lo haría en forma radicalmente distinta, y al mismo tiempo es probable que de oir la transcripción novelesca, ninguno de ellos la reconocería.

Por otra parte, la ordenación de los detalles, por más que siga un orden ascensional, el del objeto mismo obedece a un ritmo peculiar de la frase, el cual-produce un sentimiento de vértigo -que el objeto de por sí no explica y que no traduce la realidad de las cosas, tampoco el estado de exaltación de los espectadores, sino la revelación de lo absurdo- algo permanentemente absurdo tras lo rutilante de las imágenes: esa revelación que invade al escritor y asimismo a un lector atento, menos preocupado por los episodios de la novela que por el halo emotivo que los rodea. Lo que un lector superficial no percibe: se aburre de tantos detalles, no entiende el por qué de tanta insistencia.

Basta adelantar los nombres de Proust o de Joyce para señalar la importancia del tema del "tiempo" en la novela del siglo XX. Estudios recientes nos han mostrado además. que todo escritor, consciente -o inconscientemente, manifiesta un "tiempo" particular. No cabe duda que fué Flaubert el primer novelista en prestar una atención detenida al problema de la traducción temporal y en resolverlo de un modo decididamente personal. Zonas de tiempo quieto estacionatio: ehtiempo de las descripciones, en pretérito imperfecto; y mutuaciones bruscas, saltos por encima de largos períodos: el tiempo de la acción, del pretérito definido. No puedo entrar en análisis apasionantes, pero que a su vez requerirían tiempo y nos obligarían a leer largos fragmentos de la novela. 'Sólo quiero indicar cómo semejante preocupación sitúa una vez más a Flaubert al antípoda de los realistas contemporáneos y contribuye a crear la "iluminación" tan propia de su obra, - a ofrecernos una vistón y no un espectáculo daguerrotipado.

A ese mismo fin concurre un procedimiento como el del contrapunto - sorprendentemente moderno- y cuyo ejemplo más famoso es la escena de los Comicios Agrícolas, cuando Emma y Rodolfo presencian escondidos la ceremonia y su dúo amoroso acompaña el discurso oficial, ridículamente hueco y ampuloso del Consejero de la Prefectura - pero procedimiento que volvemos a encontrar en el curso del libro cada vez que divergen (o más ra. 
ramente parecen coincidir) los sentimientos de los personajes: esposo y esposa- Emma y Carlos; amantes - Emma.y León-o cada vez que las pasiones de los protagonistas se destacan en el fondo contradictorio de la indiferencia, la estupidez o la adversidad: Emma y León en la catedral de Roma, Emma y Leán en el coche de alquiler, etc.

Hemos recordado las palabras de Flaubert sobre la poca importancia que él daba a la trama de sus novelas. Pero ya advertíamos que la anécdota no era totalmente indiferente, puesto que Emma Bovary, tal como la conocemos, habría surgido de la imposibilidad de dar vida a "una solterona casta y cucufata". Por otro lado tenemos la declaración del novelista: "Madame Bovary, soy yo", que identifica al creador con su personaje principal, tan lejos de él a primera vista, y destruye la hipótesis de un arte gratuito, impasible que engañara a muchos lectores. No necesitamos siquiera tomar en cuenta un primer Flaubert, el de la juventud; autor de confesiones descabelladas - Memorias de un Loco, Noviembre, posteriormente despreciadas por el Flaubert de la madurez. Pero, "ya que de realismo se trata" - para volver a citar a Baudelaire- ya que de realismo se trata, no olvidemos que la reacción contra el romanticismo, en tiempos del Segundo Imperio fué, al mismo tiempo que una reacción formal, artística, una reacción de la inteligencia crítica contra la egolatría inmediata y por lo general carente de estilo (intencionalmente empleo de nuevo la palabra). Ello no implica que el escrito desaparezca de su obra; por lo menos en los verdaderos creadores, una vez desterradas las circunstancias de la biografía, se nos revela una figura más profunda, perturbadora de los conflictos, y como diríamos hoy día, de la "elección" fundamental, ésencial de cada artista. El pudor, la discreción, cierta ironía y el mayor cuidado de la forma no acaban con el lirismo, sino que más bien lo purifican e intensifican. Apenas empieza a hablar Baudelaire, nos apartamos de Musset, cuyos gritos de pasión ya muy poco nos conmueven.

Cuando Flaubert declara: "Madame Bovary soy yo", se expresa como hombre de la generación de Baudelaire, y más importante que de una generación puramente histórica, de la familia espiritual de Baudelaire. No se refiere a la sucesión de episodios de la novela, a la historia circunstanciada de Emma, pequeña burguesa provinciana, que no es dueña de sus emociones y sucumbe al desorden de su mente y de su corazón: Pues es evidente que aplica a la heroína (¿podemos llamarla heroína?) la 
misma atención despiadada que a los otros personajes -digo la misma, y no es exacto- una atención mucho más despiadada, mucho más implacable, tanto que si algunas figuras secundarias no pasan de ser fantoches entrevistos, Emma, paradójicamente, llega a compartir esa condición de "fantoche", no por carencia de detalles, al contrario, por el exceso mismo de los detalles. Sin embargo hay una página, en el centro de la novela, que ha de detenernos porque Flaubert sin renunciar a su acostumbrada impasibilidad, introduce una diferencia entre los personajes $y, a$ pesar de no insistir, no puede ocultar cierta simpatía hacia Emma, simpatía exclusiva de quienes rodean a la desgraciada mujer.

El momento más fogoso del amor entre Emma y Rodolfo: ella se entrega sin ningún reparo, pero él, que tiene o cree tener matodas aquellas que la precedieron; y por tanto la reduce a un deyor experiencia amorosa, ya empieza a comparar a su amante con nominador común que niega su individualidad, altera el sentido de sus discursos y de sus actos, Flaubert comenta - describe, pero simultáneamente comenta: "Porque labios libertinos o venables le habián murmurado (a Rodolfo) frases idénticas (a las de Emma), él difícilmente creía en el candor de los últimos; era preciso desconfiar, pensable, pues los discursos exagerados ocultan las afecciones mediocres; como si a veces la plenitud del alma no rebosara en las metáforas más vacías, "ya que nadle, nunca, puede dar la exacta médidade sus necesidades, ni de sus concep clones, ni de sus dolores, y la palabra humana es como una caia destemplada en la que tocamos melodias para que ballen los osos, cuando quisiéramos enternecer a las estrellas".

La generalización: "nunca, nadie", el empleo del plural: nosotros - rebasan el personaje de Emma y extienden la nostalgia, colorean con una nota pesimista universal la historia que el escritor parecía contarnos sin participar en la sucesión de los trances. En realidad un escritor como Flaubert no adopta un "tema", que muy bien hubiera podido ser otro, sino para mejor verter, en la objetividad del relato, la obsesión de toda su vida que, tal cual ocurre a quienes viven con la mayor intensidad, resulta de una sorprendente sencillez, pero en obsesión de todos los instantes; y la obra no tiene más objeto que el de manifestarla.

La biografía de Madame Bovary en nada corresponde a una biografía de Flaubert; hasta es probable que haya sido el amigo del autor, Maxime du Camp quien le propusiera como materia de su libro la triste existencia del Delphine Couturier, esposa Dela- 
mare. Pero no importa el origen de la novela, tampoco importa la relación entre Madame Delamare y Madame Bovary; la segunda es para nosotros la única con vida, con realidad. Nos referimos una última vez testimonio de Baudelaire: él no conocía la reflexión de Flaubert ya citada, y no obstante, con singular penetración, no vaciló en reconocer que la criatura retratada por el novelista no podía ser limitada a los episodios vulgares de la historia. "En suma, esa mujer es verdaderamente grande, es sobre todo digna de lástima, y a pesar de la dureza sistemática del autor, que se ha esforzado en permanecer ausente de su obra y hacer las veces de un presentador de títeres, todas las mujeres intelectuales le quedarán agradecidas por haber levantado a la hembra a tan alta potencia, tan lejos del puro animal, y tan cerca del hombre ideal, y haberla hecho partícipe del doble carácter del cálculo y ensueño que constituye al ser perfecto".

Mucho habría que decir sobre los tópicos tan personales que Baudelaire introduce en su crítica; ya que estamos hablando de Madame Bovary, bástenos subrayar el carácter varonil que el poeta señala en el personaje de Emma -imaginación, energía, dàndismo, amor exclusivo de la dominación- todos rasgos distintivos del hombre -al menos de cierto tipo de hombre "nervioso", de acuerdo a definiciones baudelarianas, y que podemos relacionar con la fórmula de Flaubert: "Madame Bovary, soy yo" .Tan es así que, en la pintura de los segundos amores de Emma y de

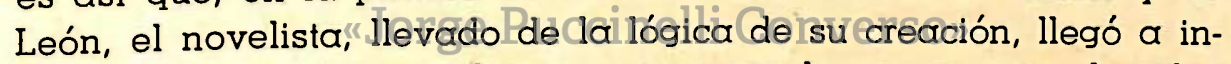
dicar como un intercambio, un trueque de sexos entre los dos amantes: "El no discutía sus ideas (de ella); aceptaba todos sus gustos; se volvía su querida mucho más que ella la querida de él"; Emma exasperada por la poca energía de León, no tardará en pensar que éste es "incapaz de heroísmo, débil, trivial, más blando que una mujer, además de avariento y pusilánime".

Tal cual es, con todos sus límites, con sus pequeñeces, Emma ejemplifica las "insufiaencia de la vida... el pudrimiento instantáneo de todas las cosas" en que creíamos apoyarnos. No olvidemos que desde joven, Flaubert convencido de la vanidad de toda esperanza y físicamente hastiado por la estupidez general, de la cual escribe: " $Q$ Qué bien la conozco! Es el objeto constante de mi estudio. Ella, nuestro mayor enemigo, hasta diría nuestro único enemigo..." no olvidemos que Flaubert, sin fe alguna en la vida, no encontrara otra razón de seguir viviendo que un gran amor, pero tan idealizado que nada le corresponde en la realidad. 
Eco de frustración definitiva hallamos en las reflexiones inspiradas por Emma: "Ah! si en el frescor de su belleza, antes de que la mancillara el matrimonio y la desilusión del adulterio, ella hubiese podido asentar su vida en un gran corazón firme, entonces, confundiendo la virtud, la ternura, el goce sensual y el deber, nunca se hubiera desprendido de tan alta felicidad. Pero aquella dicha era probablemente una mentira imaginada para la desesperación de todo deseo".

"Una mentira imaginada por la desesperación de todo deseo"; Emma Bovary manifiesta, a su manera, el abismo entre el sueño de la vida y la realidad de la vida - un abismo del que ninguna ilusión puede hacer que Flaubert aparte nunca la vista. Hasta ahí la asimilación del personaje con el escritor, la cual no consiste en una identidad de aventuras, tampoco de psicología cotidiana, sino en un fondo común de insatisfacción que bien podríamos calificar de metafísica. De todos modos -la identificación no es total: el personaje no alcanza la suma "conciencia", la lucidez del novelista y se separa de él al mismo tiempo que lo representa. Emma se hunde en su propia historia, mientras que Flaubert la está mirando desde afuera ( $y$ por eso otro personaje tal vez hubiera expresado con igual acuidad una visión de la vida que no sólo depende de las circunstancias). Si comparte su profundo desengaño, Flauberte odia el sentimentalista de Emma; ella persiste mucho en tener ilusiones y conforme las va perdiendo, trata de inventarse otras, hasta más no poder; él ha aprendido, temprano a renunciar a todas las quimeras, a no caer en la trampa de los propios sentimientos, a no esperar de la vida lo que ésta nos niega al nacer.

Durante largo tiempo, Emma oponía la vulgaridad de su propia vida y la "embriaguez", la "pasión" de otra vida tal como sus libros se la presentaban; creía que la poca felicidad se debía a su mala suerte, pero que algo podía suceder que cambiara su isituación, su suerte: "Le parecía que ciertos lugares en la tierra producían forzosamente la dicha" y que el alcanzarlos significa alcanzar también la segunda: quimeras de la adolescencia que Emma prolonga como todos los sentimentales desprovistos de sentido crítico y simultáneamente de recato o de modestia, con el ejemplo de una mala literatura aceptada al pie de la letra. Emma lee novelas, pero Flaubert las escribe.

"Ella tenía que sacar de las cosas una especie de provecho inmediato; y rechazaba como inútil cuanto no contribuía al con- 
sumo inmediato de su corazón - siendo de temperamento más senimental que artista, buscando emociones y no paisajes". Si analizaramos en detalle el personaje de Emma Bovary, sería preciso insistir en la "bulimia" especial que la caracteriza. Pero ahora fijémonos solamente en la oposición que Flaubert establece entre un temperamento sentimental y un temperamento artista -más desinteresado, contemplativo, sensible a otra clase de goce 0 de satisfacción. Flaubert que en nada creía, creía en el Arte. El mundo es absurdo, y pesimista el hombre que lo considera, pero con el furor de un bárbaro y al mismo tiempo la aplicación de un benedictino, el artista luchando contra el hastío que lo amena$z a$ por medio de un continuo trabajo, se adueña de la realidad y, sin negarla, la transfigura, le da un estilo: única victoria posible del hombre sobre la fatalidad. Riqueza del universo y de la imaginación humana, pobreza de la vida $y$ de nuestros destinos -el arte sólo logra resolver tal pobreza y tal riqueza superándolas. De regreso de Cartago, en junio de 1858, y a punto de emprender una nueva obra Salambó, Flaubert, invocando a un Dios en el cual no tiene fe, exclamaría, exaltando el poder redentor de la Belleza: "Que todas las energías de la naturaleza que he aspirado, me penetren y se exhalen en mi libro. Venga a mí, potencias! de la emoción plástica...! Hay que hacer, a través de lo Bello, algo viviente $\mathrm{y}$ verdadero a pesar de todo. Ten piedad de misvoluntad, Dios de las almas, dáme la Fuerza y la Esperanza...

Al final de Madame Bovary, Emmd ha muerto, Charles también ha muerto. La última frase del libro consagra el reino de la estupidez, la peor de todas: pedante y petulante -la de Homais: "Tiene una clientela infernal. La autoridad lo considera y la opinión pública lo protege.

Acaba de recibir la "Legión de Honor". Pero si los poderes oficiales sellan el triunfo del boticario, la magia del artista -único rebelde absoluto - trasciende la necia amargura de la realidad y llena, sol, la espera del deseo.

Noviembre de 1957. 